\title{
Reflections on the immunology of tuberculosis: will we ever unravel the skein?
}

\author{
Maurizio de Martino*, Luisa Galli, Elena Chiappini
}

\begin{abstract}
Many and large dumps exist in our knowledge about Mycobacterium tuberculosis infection and disease in infants and children. We still do not understand why some individuals do acquire and others do not acquire the infection in the presence of the same risk factors. We do not understand why some individuals convert from latent to active tuberculosis and why other individuals convert from active to inactive tuberculosis even without treatment. As a matter of fact the immune system mounts a bouncing, robust and polyedral defence against Mycobacterium tuberculosis, but the bacillus is so much artful and dextrous that it has ahead from this immunological fierce accoutrements. Mycobacterium tuberculosis survival, multiplication, and transmission are largely favoured by the immune mechanisms. The granuloma itself is more bacillus- than host-protective.

These abilities make Mycobacterium tuberculosis one of more successful human pathogens, but dumps in our knowledge and the counterproductive immunity hinder development of new diagnostics, therapies and vaccines. This occurs in front of an infection which engages one third of the world population and a disease which kills in a year about 1.5 million individuals worldwide.

Understanding mechanisms and meaning of immune response in tuberculosis marks out the foundations of strategies with a view to prepare effective vaccines and reliable diagnostic tools as well as to build up therapeutic weapons. To gain these objectives is vital and urgent considering that tuberculosis is a common cause of morbidity and is a leading cause of death.
\end{abstract}

Tuberculosis is a paradox disconcerting for immunologists since a good immune response is developed in most individuals, but this response does not just eliminate the infection. On the contrary it aids the survival of Mycobacterium tuberculosis, assists its replication and transmission and induces the bacterium to adopt a silent underhand state from which it can reactivate as it pleases [1-4].

In addition, we would like to understand why some individuals do acquire whilst others do not acquire the infection (exposure conditions being equal), why some rare individuals get rid of infection, and how some individuals (without any treatment) are able to convert an active into an inactive infection [5].

\section{In spite of innate immunity, mycobacteria organize their bridgehead}

Paraphrasing a famous aphorism of general Erwin Rommel, with regard to the amphibious warfare, but

\footnotetext{
* Correspondence: maurizio.demartino@unifi.it

Department of Health Sciences, Meyer Children University Hospital, University of Florence, Florence, Italy
}

(c) 2014 de Martino et al; licensee BioMed Central Ltd. This is an Open Access article distributed under the terms of the Creative Commons Attribution License (http://creativecommons.org/licenses/by/2.0), which permits unrestricted use, distribution, and reproduction in any medium, provided the original work is properly cited. The Creative Commons Public Domain Dedication waiver (http://creativecommons.org/publicdomain/zero/1.0/) applies to the data made available in this article, unless otherwise stated.

well appropriate in the contest of tuberculosis, all is decided the first day, which gets the longest day.

Sometimes, soon after inhalation of Mycobacterium tuberculosis, bacilli are phagocitized by alveolar macrophages which can kill them and settle the case. This probably depends the coincidence of lucky factors including an intrinsic capacity of macrophages to generate reactive oxygen intermediates (ROI) and consequent microbicidal activity, a favorable inflammatory environment at the infection site, and not outstanding pathogenetic abilities of the inhaled strain [4].

If bacilli survive during the longest day (this is the commonest occurrence) they have won the fight. They proliferate at a logarithmic rate within dendritic cells and alveolar macrophages inducing the production of proinflammatory cytokines including interleukin (IL)$1-\alpha$, IL-1 $\beta$, tumor necrosis factor Ianus Bifrons, IL-6, IL-12, and interferon (IFN)- $\gamma$ [2-4].

The role of these cytokines calls to mind the myth of Ianus bifrons: IFN- $\gamma$ regulates T-cell response to mycobacterial infection, promotes antigen presentation, activates 
phagocytosis, production of ROI, TNF- $\alpha$ mediates early inflammatory responses against infectious agents also stimulating IL-1 and IL- 6 production. The susceptibility to mycobacterial infection of TNF- $\alpha$ deficient the mice (which is unable to undertake the formation of granuloma: but, it desirable or not? See afterwards), the increased susceptibility to bacillus of Calmette and Guérin (BCG; formerly vaccin Bilié de Calmette et Guérin) infection in mice who received anti-TNF- $\alpha$ antibodies and the mycobacterial susceptibility of human treated with TNF- $\alpha$ blockers should suggests its protective role. Also IL-6 is fundamental in developing the early inflammatory response. Its absence in mice may inhibit the maintenance of the protective (may be) IL-17 and causes a delayed IFN$\gamma$ production and consequently determines an increased mycobacterial burden. It is well known that IL-12 promotes the $\mathrm{TH}-1$ response and that its deficiency is associated in humans with an increased susceptibility to mycobacterial infection $[3,4,6,7]$

This first immune mechanism is largely mediated by molecules of the innate immunity. A large number of them are involved, including multiple pattern recognition receptors (that is toll-like receptors), C-type lectin receptor family, cytosolic pattern-recognition receptors, pyrin domain containing 3 , and nucleotide-binding oligomerization domain protein 2 . These molecules recognize as many again a number of mycobacterial products such as lipoproteins, lipomannans, and DNA [8-12].

The main consequence of recognition of mycobacterial molecules by innate immunity molecules is not only the expression of pro-inflammatory cytokines, but also the expression of cellular adhesion molecules and chemokines which mobilize and activate macrophages, dendritic cells, and neutrophils [11].

In many other infectious diseases this activity should be considered commendable and useful [1]. Instead, in tuberculosis, the inflow of these phagocytic cells supplies a lot of cellular niches that allow the mycobacteria to grow without hindrance $[1,13,14]$. The mycobacterial population grow and spread to freshly recruited adjacent uninfected cells. This is preceded (admirable strategy) by a prolonged survival of the infected cell caused by the Mycobacterium tuberculosis itself. In fact, Mycobacterium tuberculosis inhibits the cell apoptosis also allowing a larger number of bacteria are accumulated before bacteria go out of the dead cell [15]. By means of this mechanisms, the induction of the adaptive immunity is delayed [15]. Also cell death is regulated by the $\mathrm{Myco-}$ bacterium of ttuberculosis. In fact, the virulence factor ESX1 type VII secretion system allow the bacteria to induce cell death, allowing them a well-timed exit [16]. It is well known that Mycobacterium bovis (used in the BCG vaccine) is devoid of the ESX1 type VII secretion system [17].
In few words: during this first stage of the immune response managed by the innate immunity, the Mycobacterium tuberculosis overcomes in big styles.

\section{The armed equilibrium during the adaptive immunity phase}

Whereas the adaptive immunity to influenza virus is recruited after 20 hours, innate immunity against tubercular infection is activated after more than a 40 days. Likely, this delay is due to the delayed transport by dendritic cells of live mycobacteria from the lungs to the draining lymphonodes $[1,18]$. This delayed transport is caused by the inhibition of transport (which should be stimulated by ligands for the CC-chemokine receptor 7) mediated by Mycobacterium tuberculosis [18]. The activation of the adaptive immunity, with an accumulation of effector $\mathrm{CD} 4^{+}$ and $\mathrm{CD}^{+} \mathrm{T}$-cells in the lungs, open a period of trench warfare during which the bacterial load remains stable. Thus the adaptive immunity is not able to eliminate the infection but not even to reduce its entity. Since during this period of apparent immunological equilibrium mycobacteria accumulate mutations and a subset of bacteria insist to replicate [1].

Some of the mechanisms which cause this defeat are proper to immune cells and include expansion of Foxp3expressing regulatory T-cells, defective antigen recognition, and reduced macrophage major histocompatibility complex expression and antigen processing [19]. Other mechanisms are proper to the Mycobacterium tuberculosis and include the resistance to the activation of macrophage function mediated by IFN $-\gamma$ and blinding of specific $\mathrm{CD} 4^{+}$ $\mathrm{T}$-cell receptors caused by the downregulation of some genes which determine the vanishing of sensible microbial antigens. During this period, nitric oxide, carbon monoxide, and hypoxia predominate in the infection microenvironment causing the expression of a regulon (controlled by the signal transduction system DosR-DosS) which allows Mycobacteria use lipids as an alternative energy source [20].

During the adaptive immunity phase phase, a balance between $\mathrm{T}_{\mathrm{H}} 1$ (and consequent IFN- $\gamma$ production) and $\mathrm{T}_{\mathrm{H}} 17$ (and consequent IL-17 production which causes neutrophil recruitment and tissue damage) cells can control bacterial growth and limit immunopathology [21].

During this phase $\gamma \delta \mathrm{T}$-cells play a significant defensive role [22]. Mycobacterium tuberculosis activate $\gamma \delta \mathrm{T}$-cells but also infected monocytes are efficient accessory cells for $\gamma \delta \mathrm{T}$-cells in a non-major histocompatibility complexrestricted also by means of IL- 15 . Analogously to $\alpha \beta \mathrm{T}$-cell receptor $^{+}, \gamma \delta$ T-cells optimize their function interacting with adhesion molecules and other molecules including CD40-CD40L, CD28-B7.1/7.2. $\gamma \delta$ T-cells produce both TNF- $\alpha$ and IFN $-\gamma$. Release of IFN- $\gamma$ is more efficient that that from $\mathrm{CD} 4^{+} \mathrm{T}$-cells. 
During this second phase, Mycobacteria do not gain ground, but gain a crucial strategic victory: they preserve and reinforce their bridgehead. Thus far the infected subject has the latent tuberculosis. One third of the world's population have been infected with Mycobacterium tuberculosis and have this form of tuberculosis [23].

\section{The attack: from latent to active tuberculosis}

At the right moment (right by the point of view of Mycobacterium tuberculosis) the resuscitation-promoting factor may be activated, even years and years after initial infection, resuscitating bacteria from the nutrient-starved state and determining the establishment of an active symptomatic disease. Sometimes (especially in areas with a high prevalence of infection) active disease is determined by re-infection with a second strain. The latent infection turn into an active infection. This change may be due to mycobacteria as well as to the host [1].

Differently from viruses (which have fixed programs of expression of their genes), mycobacteria are able to change expression of their genes according to necessities and stimuli which are derived from the environment. Thus mycobacteria can change the expression of their surface antigens and evade T-cell recognition. In mice mycobacteria persist in the lungs also because, as soon as $\mathrm{CD} 4^{+}$and $\mathrm{CD} 8+\mathrm{T}$-cells enter the lungs, ESAT6 and Ag85B antigen expression is downregulated [24].

The host counterpart of re-activation may be an immunological low on guard [25]. Mechanisms are very poorly understood. Some model exist, including anti-TNF monoclonal antibodies used in a number of autoimmune disease, treatments with steroids, and the $\mathrm{CD} 4^{+}$loss in patients with human immunodeficiency virus-type 1 (HIV-1) infection . Interestingly, re-activation in HIV-1 patients occurs largely before the nadir of $\mathrm{CD} 4^{+}$ cells, because HIV-1 selectively eliminates Mycobacterium tuberculosis antigen-specific $\mathrm{CD} 4^{+}$cells at a higher rate than other antigen-specific $\mathrm{CD} 4^{+}$cells.

possible that this is a more general mechanism of $\mathrm{T}$ cell exhaustion in tuberculosis since the mycobacterial load in the lungs is inversely related to the proportion of blood antigen-specific T-cells. In addition, unfavourable polymorphisms of chemokines may alter the cell trafficking in the lungs a reduce the recruitment of cells which should contain the infection. It has been reported that some patients with latent TB have signatures similar to those in patients with active TB. They manifest a specific 86-transcript active TB. This signature is dominated by a neutrophil-driven IFN-inducible gene profile, consisting of both IFN $-\gamma$ and type I IFN- $\alpha \beta$ signalling [26]. These findings underscore the role of IFNs and neutrophils in the development of active tuberculosis

More vague are other possible mechanisms [1]. One is the supposed longer delay in the development of adaptive immunity (observed in the diabetic mice and possibly caused by difficulties in the movement of dendritic cells from the lungs to the lymph nodes) which could explain the increased frequency of re-activation in the diabetic patient. It is an old story that thinnish people (besides their nutritional status) are more prone to tubercular re-activation. This association may depend on leptin which regulates, besides appetite, also growth and activity of $\mathrm{T}_{\mathrm{H}} 1$ cells.

As a proof that this second stage of immune response managed by adaptive immunity is a dynamic process of shooting war, the patients may present fever and erythema nodosum [27].

\section{Only sometimes immunity holds on tightly}

Even though the mechanisms are unexplored, it is known that active infection is not a single track. In fact, a substantial but anyway minority portion of patients with active tuberculosis can succeed in getting rid of infection and lead to an inactive tuberculosis. Whereas patients with latent tuberculosis do not manifest chest-X-rays findings, subjects with inactive tuberculosis have chest-X-rays changes [1].

Memory $\mathrm{T}$ cells are distinguished by function and migratory capacity. Central memory T-cells have high proliferative activity and produce IL-2, whereas effector memory T-cells produce bothIL- 2 and IFN- $\gamma$. Circulating effector memory $\mathrm{T}$-cells indicates that an antigen-specific response persists, whereas circulating central memory T-cells indicate that infection has been controlled [28].

Subjects with inactive tuberculosis evidence CD $4^{+}$ central memory $\mathrm{T}$-cell response. By contrast, patients with active tuberculosis evidence $\mathrm{CD} 4^{+}$effector memory T-cell responses [29].

\section{Mycobacteria flood}

The ultimate objective of all living beings is to disseminate as much as possible their genetic stock. It could seem unbelievable, but the adaptive immunity does favour the transmission of mycobacteria [1].

For transmission mycobacteria need a large surface exposed to the exterior. This surface allows the mycobacteria are expelled by an infected (and coughing) patient with active tuberculosis, reach and infect a previously uninfected individual $[30,31]$

A large surface is obtained by means the development of cavitary tuberculosis which is the result of lung tissue destruction. There are several lines of evidence, deriving from the HIV-1 infection model, suggesting that T-cells contribute to the development of cavitary tuberculosis: 1 ) HIV-1 infected subjects less frequently have cavitary tuberculosis; 2) HIV-1 infected patients less frequently transmit mycobacteria as compared to HIV-1 uninfected people; 3 ) in $\mathrm{HIV}-1$ infected patients more the $\mathrm{CD} 4^{+}$ 
T-cells and more the frequency of cavitary tuberculosis. Mechanisms are unknown. In very general terms it can be supposed that T-cells promote a high level of inflammation which damage lung tissue [32].

As a matter of fact, strains of Mycobacterium tuberculosis diverged genetically many and many years ago (to give an idea: during the upper paleolithic, roughly at the end of the last ice age), but all strains have conserved epitopes which are just that recognized by T-cells [33]. When something is preserved by a species for a long time during evolution it means that it is fundamental for survival of the species. From this we may conclude that for Mycobacterium tuberculosis it is an evolutionary advantage to be recognized by $\mathrm{T}$-cells $[34,35]$.

\section{Granulomata: friend or foe?}

Richard Morton descovered in 1679 granuloma (at the time termed tubercles) and described it in his book entitled Phthisiologia more than two centuries before the discovery of the agent causing tuberculosis [36].

Epithelial granulomata are the hallmark of tuberculosis. For a long time it has been believed that these evolutionarily primitive structures control the infection since they wall out bacilli. Unfortunately, it is not so [37-39].

An (apparently) hardened and dynamic arsenal of well organized immunity cells is concentrated in tubercular granulomata. T-cells, B-cells, neutrophils, fibroblasts, macrophages (infected or uninfected), epithelioid cells derived from macrophages, foamy macrophages, and multinucleated giant Langehans cells make up the tubercular granulomata. Granulomata development starts shortly after infection. At the beginning an innate granuloma develops which is composed by neutrophils and alveolar macrophages. Unfortunately, mycobacteria within granulomata are able to disarm alveolar macrophages arresting the phagolysosome fusion thus blocking the killing of internalized mycobacteria. Mycobacteria also drive in infected and harmless (by the point of view of mycobacteria) macrophages the production of chemoattractant and pro-inflammatory cytokines. In addition, the relase by mycobacteria of the $6 \mathrm{kDa}$ early secretory antigenic target causes the activation of the epithelium which stimulates the recruitment of macrophages causing the expression of matrix metalloproteinase-9 (MMP-9). Also the expression of MMP-1 is driven by mycobacteria [40-42]

The result of this frantic fascination towards immune cells is the development of the immune granuloma and the multiplication of fresh pabulum for mycobacteria. Mechanisms involved in the promotion and development of granulomata are mostly driven by mycobacteria and this clearly suggests that all is done in the mycobacteria's own interest [42].

TNF is believed to be fundamental for defence against Mycobacteria and for granuloma formation. Howeever, its iatrogenic inhibition disrupts granuloma allowing replication of mycobacteria and thus increases the efficacy of chemotherapics [43].

Thus, contrary to the traditional view of a protective role of granulomata, it is now convincing that granulomata favour the persistence and diffusion of the mycobacteriun more than its segregation or even its elimination.

\section{B-cells and antibodies: intelligence agents, ancillary services, or useless?}

The role of humoral immunity in tuberculosis is, at the very least, evanescent. On the one hand there are the inconsistent findings in studies of passive immunization, the irrelevance of humoral deficiencies and B-cell immune defects in Mycobacterium tuberculosis infection and disease and the ambiguous results in knockout mice besides the general rule that antibodies are nearly ineffective against intracellular agents [44-47].

On the other hand, there are well known exceptions to this rule (infections caused by species of Leishmania, Chlamydia, Francisella), the levels of specific antibodies correlate to the efficacy of BCG vaccine, mice knockout for polymeric immunoglobulin receptors have a higher susceptibility to mycobacterial infections (is there a role of mucosal dymeric IgA?), in animal models monoclonal antibodies against mycobacterial antigens have a beneficial effect in tuberculosis. In addition, there is evidence that Bcells are a fundamental component of granulomata and follicle-like B-cell aggregates (site of antigen presentation to T-cells?) are a characteristic feature of granulomatous progession in mycobacterial infection.

In a broader view it is well known that B-cells and humoral immunity collaborate with T-cells and cellular immunity in almost all infectious diseases and B-cells act as antigen-presenting cells to T-cells.and/or polarize $\mathrm{T}$-cell activity influencing the production of cytokines. $B$-cells are deeply involved in the production in the lungs of the anti-inflammatory IL-10.

It is a peculiar finding that sometimes these mechanisms work in the presence of B-cells, but in the absence of antibodies. Sometimes the opposite occurs. Even more singularly, in tuberculosis and particularly in active tuberculosis there is an significantly elevated prevalence of subjects with autoantibodies [48].

\section{Conclusions}

Tuberculosis is a major international public health. Great efforts are being made by science to oppose this plague. But, candidly, translational results are still stalling.

Each human (and his/her immune mechanisms) is very similar but also largely differ from other humans (and their immune mechanisms). Maybe that personalized medicine is the way to unravel the skein. Results of how immune gene polymorphisms and, in particular, 
polymorphisms concerning how toll-like receptor and autophagy-related genes influence tuberculosis susceptibility and clinical course are consistent with line of thinking [49-51]. Maybe that some immunological dogma should be revised. One of many is the ambiguous role of IFN- $\gamma$ [52]. Maybe that some branch of research should be implemented. One is that concerning the unaccountably underestimated role of $\gamma \delta \mathrm{T}$-cells [22]. Maybe that, if we want to win the fight against Mycobacterium tuberculosis, we must renounce to conformism. It is time for a different way of thinking.

\section{Abbreviations}

BCG: bacillus Calmétte Guerin; IFN: interferon; IL: interleukin; MMP: metalloproteinase; ROI: rective oxygen intermefiate; TNF: tumor necrosis factor.

\section{Competing interests}

the authors declare that they have no competing interests.

\section{Authors' contributions}

MdM conceived the idea, collected data from the literature, and drafted the manuscript. EC and LG helped to draft and critically reviewed the manuscript.

\section{Declarations}

Funding for this supplement has come from a grant of the Italian Health Ministry / Young Research Project.

This article has been published as part of BMC Infectious Diseases Volume 14 Supplement 1, 2014: Highlights in Pediatric Tuberculosis. The full contents of the supplement are available online at http://www.biomedcentral.com/ bmcinfectdis/supplements/14/S1

Published: 8 January 2014

\section{References}

1. Ernst JD: The immunological life cycle of tuberculosis. Nature Rev 2012, 12:581-591.

2. Zumla A, Raviglione M, Hafner R, von Reyn F: Tuberculosis. N Engl J Med 2013, 368:745-755

3. Cooper AM, Torrado E: Protection versus pathology in tuberculosis: recent insights. Curr Opin Immunol 2012, 24:431-437.

4. Zuňiga J, Torres-Garcia D, Santos Mendoza T, Rodriguez-Reyna TS, Granados J, Yunis EJ: Cellular and humoral mechanisms involved in the control of tuberculosis. Clin Develop Immunol 2012, ID 193923 doi: 10.1155/2012/193923.

5. Roy RB, Whittaker E, Kampmann B: Current understanding of the immune response to tuberculosis in children. Curr Opin Infect Dis 2012, 25:250-257.

6. Cooper AM, Adams LB, Dalton DK, Appleberg R, Ehlers S: IFN- $\gamma$ and NO in mycobacterial diseases:new jobs for old hands. Trends Microbiol 2002, 10:221-222.

7. Kaufmann SHE: How can immunology contribute to the control of tuberculosis? Nature Rev Immunol 2001, 1:20-30.

8. Kim JS, Kim WS, Choi HG, Jang B, Lee K, Park JH, Kim HJ, Cho SN, Shin SJ: Mycobacterium tuberculosis RpfB drives Th1-type T cell immunity via a TLR4-dependent activation of dendritic cells. J Leukoc Biol 2013, [Epub ahead of print.

9. Bafica A, Scanga CA, Feng CG, Leifer C, Cheever A, Sher A: TLR9 regulates Th1 responses and cooperates with TLR2 in mediating optimal resistance to Mycobacterium tuberculosis. J Exp Med 2005, 202:1715-1724.

10. Banaiee N, Kincaid EZ, Buchwald U, Jacobs WR Jr, Ernst JD: Potent inhibition of cytokines in the balance of protection and pathology during mycobacterial infections. Adv Exp Med Biol 2013, 783:121-140.

11. Thada S, Valluri VL, Gaddam SL: Influence of toll-like receptor gene polymorphisms to tuberculosis susceptibility in humans. Scand J Immunol 2013, 78:221-229.
12. Torrado E, Cooper AM: Macrophage responses to IFN- $\gamma$ by live virulent Mycobacterium tuberculosis is independent of mature mycobacterial lipoproteins but dependent on TLR2. J Immunol 2006, 176:3019-3027.

13. Chackerian AA, Alt JM, Perera TV, Dascher CC, Behar SM: Dissemination of Mycobacterium tuberculosis is influenced by host factors and precedes the initiation of T cell immunity. Infect Immun 2002, 70:4501-4509.

14. Huynh KK, Joshi SA, Brown EJ: A delicate dance: host response to mycobacteria. Curr Opin Immunol 2011, 23:464-472.

15. Blomgran R, Desvignes L, Briken V, Ernst JD: Mycobacterium tuberculosis inhibits neutrophil apoptosis, leading to delayed activation of naive CD4 T cells. Cell Host Microbe 2012, 11:81-90.

16. Abdallah AM, Bestebroer J, Savage ND, de Punder K, van Zon M, Wilson L, Korbee CJ, van der Sar AM, Ottenhoff TH, van der Wel NN, Bitter W, Peters PJ: Mycobacterial secretion systems ESX-1 and ESX-5 play distinct roles in host cell death and inflammasome activation. J Immunol 2011, 187:4744-4753.

17. Pym A, Brodin P, Brosch R, Huerre M, Cole S: Loss of RD1 contributed to the attenuation of the live tuberculosis vaccines Mycobacterium bovis BCG and Mycobacterium microti. Mol Microbiol 2002, 46:709-717.

18. Scott-Browne JP, Scott-Browne JP, Shafiani S, Tucker-Heard G, Ishida-Tsubota K, Fontenot JD, Rudensky AY, Bevan MJ, Urdahl KB: Expansion and function of Foxp3-expressing T regulatory cells during tuberculosis. J Exp Med 2007, 204:2159-2169.

19. Reiley WW, Calayag MD, Wittmer ST, Huntington JL, Pearl JE, Fountain JJ, Martino CA, Roberts AD, Cooper AM, Winslow GM, Woodland DL: ESAT-6specific CD4 T cell responses to aerosol Mycobacterium tuberculosis infection are initiated in the mediastinal lymph nodes. Proc Natl Acad Sci USA 2008, 105:10961-10966.

20. Black GF, Thiel BA, Ota MO, Parida SK, Adegbola R, Boom WH, Dockrell HM, Franken KL, Friggen AH, Hill PC, Klein MR, Lalor MK, Mayanja H, Schoolnik G, Stanley K, Weldingh K, Kaufmann SH, Walzl G, Ottenhoff TH: Immunogenicity of novel DosR regulon-encoded candidate antigens of Mycobacterium tuberculosis in three high-burden populations in Africa. Clin Vaccine Immunol 2009, 16:1203-1212.

21. Torrado E, Cooper AM: IL-17 and Th17 cells in tuberculosis. Cytokine Growth Factor Rev 2010, 21:455-462.

22. Meraviglia S, El Daker S, Dieli F, Martini F, Martino A: $\gamma \delta$ T cells cross-link innate and adaptive immunity in Mycobacterium tuberculosis infection. Clin Dev Immunol 2011, ID 587315. doi: 10.1155/2011/587315.

23. World Health Organization: Tuberculosis., Fact sheet no104, February 2013.

24. Rogerson BJ, Jung YJ, LaCourse R, Ryan L, Enright N, North RJ: Expression levels of Mycobacterium tuberculosis antigen-encoding genes versus production levels of antigen-specific T cells during stationary level lung infection in mice. Immunology 2006, 118:195-201.

25. Geldmacher C, Zumla A, Hoelscher M: Interaction between HIV and Mycobacterium tuberculosis: HIV-1-induced CD4 T-cell depletion and the development of active tuberculosis. Curr Opin HIV AIDS 2012, 7:268-275.

26. Berry MP, Graham CM, McNab FW, Xu Z, Bloch SA, Oni T, Wilkinson KA, Banchereau R, Skinner J, Wilkinson RJ, Quinn C, Blankenship D, Dhawan R, Cush JJ, Mejias A, Ramilo O, Kon OM, Pascual V, Banchereau J, Chaussabel D, O'Garra A: An interferon inducible neutrophil-driven blood transcriptional signature in human tuberculosis. Nature 2010, 466:973-977.

27. Poulsen A: Some clinical features of tuberculosis. Acta Tuberc. Scand 1950, 24:311-346, I. Incubation period.

28. Harari A, Dutoit V, Cellerai C, Bart P-A, Du Pasquier RA, Pantaleo G: Functional signatures of protective antiviral T-cell immunity in human virus infections. Immunol Rev 2006, 211:236-254.

29. Millington KA, Gooding S, Hinks TS, Reynolds DJ, Lalvani A: Mycobacterium tuberculosis-specific cellular immune profiles suggest bacillary persistence decades after spontaneous cure in untreated tuberculosis. J Infect Dis 2010, 202:1685-1689.

30. Rodrigo T, Caylà JA, García de Olalla P, Galdós-Tangüis $H$, Jansà JM, Miranda P, Brugal T: Characteristics of tuberculosis patients who generate secondary cases. Int J Tuberc Lung Dis 1997, 1:352-357.

31. Kaplan G, Post FA, Moreira AL, Wainwright H, Kreiswirth BN, Tanverdi M, Mathema B, Ramaswamy SV, Walther G, Steyn LM, Barry CE 3rd, Bekker LG: Mycobacterium tuberculosis growth at the cavity surface: a microenvironment with failed immunity:. Infect Immun 2003, 71:7099-7108.

32. Kwan CK, Ernst JD: HIV and tuberculosis: a deadly human syndemic. Clin Microbiol Rev 2011, 24:351-376. 
33. Kapur V, Whittam TS, Musser JM: Is Mycobacterium tuberculosis 15,000 years old? J Infect Dis 1994, 170:1348-1349.

34. Comas I, Chakravartti J, Small PM, Galagan J, Niemann S, Kremer K, Ernst JD, Gagneux S: Human T cell epitopes of Mycobacterium tuberculosis are evolutionarily hyperconserved. Nature Genet 2010, 42:498-503.

35. Blouin Y, Hauck Y, Soler C, Fabre M, Vong R, Dehan C, Cazajous G, Massoure PL, Kraemer P, Jenkins A, Garnotel E, Pourcel C, Vergnaud G: Significance of the identification in the Horn of Africa of an exceptionally deep branching Mycobacterium tuberculosis clade. PLOS One 2012, 7:e52841, doi: 10.1371/journal.pone.0052841.

36. Morton R: Phthisiologia: or, a treatise of consumptions: wherein the difference, nature, causes, signs, and cure of all sorts of consumptions are explained. $W$ and IJ Innys, London; 1720.

37. Shaler CR, Horvath $C N$, Jeyanathan $M$, Xing Z: Within the enemy's camp: contribution of the granuloma to the dissemination, persistence and transmission of Mycobacterium tuberculosis. Front Immunol 2013, 4, doi: 10.3389/fimmu 2013.00030.

38. Guirado E, Schlesinger LS: Modeling the Mycobacterium tuberculosis granuloma - the critical battlefield in host immunity and disease. Front Immunol 2013, 4, doi:10.3389/fimmu.2013.00098.

39. Ramakrishnan $\mathrm{L}$ : Revisiting the role of the granuloma in tuberculosis. Nat Rev Immunol 2012, 12:352-366.

40. Volkman HE, Pozos TC, Zheng J, Davis JM, Rawls JF, Ramakrishnan L: Tuberculous granuloma induction via interaction of a bacterial secreted protein with host epithelium. Science 2010, 327:466-469.

41. Ramakrishnan $L$ : Looking within the zebrafish to understand the tuberculous granuloma. Adv Exp Med Biol 2013, 783:251-266.

42. Davis JM, Ramakrishnan $\mathrm{L}$ : The role of granuloma in expansion and dissemination of early tuberculous infection. Cell 2009, 136:37-49.

43. Bourigault ML, Vacher R, Rose S, Olleros ML, Janssens JP, Quesniaux VF, Garcia I: Tumor necrosis factor neutralization combined with chemotherapy enhances Mycobacterium tuberculosis clearance and reduces lung pathology. Am J Clin Exp Immunol 2013, 2:124-134.

44. Phuah JY, Mattila JT, Lin PL, Flynn JL: Activated B cells in the granulomas of nonhuman primates infected with Mycobacterium tuberculosis. Am J Pathol 2012, 181:508-514.

45. Achkar JM, Casadevall A: Antibody-mediated immunity against tuberculosis: implications for vaccine development. Cell Host Microbe 2013, 13:250-262.

46. Kozakiewicz L, Phuah J, Flynn J, Chan J: The role of B cells and humoral immunity in Mycobacterium tuberculosis infection. Adv Exp Med Biol 2013, 783:225-250.

47. Maglione PJ, Chan J: How B cells shape the immune response against Mycobacterium tuberculosis. Eur J Immunol 2009, 39:676-686.

48. Shen CY, Hsieh SC, Yu CL, Wang JY, Lee LN, Yu CJ: Autoantibody prevalence in active tuberculosis: reactive or pathognomonic? BMJ Open 2013, 3, doi:pii: e002665. 10.1136/bmjopen-2013-002665.

49. Thada S, Valluri VL, Gaddam SL: Influence of toll-like receptor gene polymorphysms to tuberculosis suscepribility in humans. Scand J Immunol 2013, 78:221-229.

50. Azad AK, Sadee W, Schlesinger LS: Innate gene polymorphisms in tuberculosis. Infect Immun 2012, 80:3343-3359.

51. Songane M, Kleinnijenhuis J, Netea MG, van Crevel R: The role of autophagy in host defence against Mycobacterium tuberculosis infection. Tuberculosis 2012, 92:388-396.

52. Abebe F: Is interferon-gamma the right marker for bacille CalmetteGuérin-induced immune protection? The missing link in our understanding of tuberculosis immunology. Clin Exp Immunol 2012, 169:213-219.

doi:10.1186/1471-2334-14-S1-S1

Cite this article as: de Martino et al:: Reflections on the immunology of tuberculosis: will we ever unravel the skein? BMC Infectious Diseases 2014 14(Suppl 1):S1.

\section{Submit your next manuscript to BioMed Central and take full advantage of:}

- Convenient online submission

- Thorough peer review

- No space constraints or color figure charges

- Immediate publication on acceptance

- Inclusion in PubMed, CAS, Scopus and Google Scholar

- Research which is freely available for redistribution

Submit your manuscript at www.biomedcentral.com/submit
Biomed Central 